\title{
Healthcare workers' self-reported effect of an interventional programme on knowledge and behaviour related to infection control
}

\author{
C Tvedt, ${ }^{1}$ G Bukholm ${ }^{2,3}$
}

${ }^{1}$ Akershus University Hospital, Institute of Clinical Epidemiology and Molecular Biology (EpiGen), Loerenskog, Norway Institute of Clinical Epidemiology and Molecular Biology (EpiGen), University of Oslo, Oslo, Norway

${ }^{3}$ The Norwegian Knowledge Centre for the Health Services, Oslo, Norway

\section{Correspondence to} Christine Tvedt, Institute of Clinical Epidemiology and Molecular Biology (EpiGen). Akershus University Hospital, PB 26, 1478 Loerenskog, Norway; ratvedt@online.no

Accepted 25 February 2009 Published Online First 27 June 2010

\begin{abstract}
Introduction Adherence to infection control guidelines is low, and several efforts have been made to improve healthcare workers' performance of infection control measures. In this study, the performance and evaluation of a hospital-wide infection control programme is described. The most important measure was distribution of an infection control newsletter.
\end{abstract}

Methods In evaluation of the programme, a randomised selection of healthcare workers received a questionnaire to investigate in what degree the healthcare workers was aware of the programme and whether they reported behavioural change and refreshed knowledge as result of the programme.

Results The intervention made it possible to reach $>80 \%$ of the personnel in a Norwegian university hospital. Among those who actually read Infection Control Newsletter, 92.9\% reported that their knowledge was refreshed and $60.6 \%$ reported behavioural change. Discussion The intervention had a significant impact on nurses and nurse assistants' reports on knowledge and behaviour related to infection control. Our study supports the importance of a long-term and multimodal approach to healthcare workers in infection control work. The time and resources spent to produce and distribute the Infection Control Newsletter was an effective way to reach out to a large number of healthcare workers.

Hospital infections are serious complications that can result in prolonged lengths of hospitalisation, invalidity and sometimes death. ${ }^{1}$ The emergence of resistant pathogens and changes in hospital epidemiology make development of strategies to control hospital infections a major challenge. ${ }^{2}$ Efforts to meet the challenges are beneficent to the patients as the risk of complications is reduced and valuable for the healthcare system as medical care costs are reduced. ${ }^{2}$

Measures to prevent nosocomial infections are described in guidelines for hospital infection control and are well documented. Nevertheless, adherence to infection control guidelines reveals a great challenge, and research on how to make healthcare workers (HCWs) comply with the guidelines is important. ${ }^{3-6}$ Knowledge and acceptance of the guidelines for infection control is required, and a first step is to implement interventions to influence HCWs' attitudes towards the recommended practice. ${ }^{2-7}$ In this study, HCWs' self-reported effect on knowledge and behaviour after a hospital-wide programme on infection control is described.

\section{METHODS AND DESIGN}

This is a descriptive study, where assessments after a hospital-wide multifaceted programme on infection control is evaluated. The programme included an infection control newsletter, educational material for ward-based education and hand hygiene audits. Through HCWs' response on a questionnaire, the effects on knowledge and behaviour were measured 1 year after introduction of the programme.

\section{Settings}

Akershus University Hospital is a 450-bed university hospital with approximately 4230 employees. The intervention was performed hospital-wide, involving all wards.

\section{Intervention}

Infection control link contacts

The cornerstone of our programme was the established system of infection control link contacts (ICCs). Besides their clinical occupation as nurses, physical therapists, biomedical laboratory scientists and radiographers, they functioned as a link between their ward and the infection control team. Their main task was to update their colleagues on infection control measures through ward-based educational meetings and hand hygiene audits.

The infection control team organised a 1-year cycle of education and meetings for approximately 60 ICCs. Three main elements were implemented in this cycle to provide the ICCs with a practical tool for the ward-based activities:

- Distribution of an infection control newsletter (monthly: September to May)

- Educational material: slides for use in ward-based education (September to May)

- Hand hygiene audits (twice a year: October and April)

Infection control newsletter and educational material The infection control personnel were responsible for production of the newsletter (four A4 pages). Every month, a number of Infection Control Newsletter (ICNews) was assigned to a specific infection control issue and produced in 800 copies (table 1). The content was related to relevant guidelines, and feedback on hospital surveillance programmes was presented. Each ward was provided with 10 to 15 copies, and key personnel as physicians and ward management (486 persons) received the ICNews in their mailbox.

With each number of ICNews, the ICCs were provided with educational material consisting of four to five power point slides related to the current infection control issue of ICNews. The ICCs were 
Table 1 Infections control issues for each ICNews number (September to May 2003/2004)

Hospital infection surveillance
MRSA
Hand hygiene
Vaccination
Infection control link contacts
Blood injuries
Isolation precautions
Bloodstream infections
Presentation of EpiGen and the Department of Microbiology

ICNews, Infection Control Newsletter; MRSA, methicillin-resistant staphylococcus aureus.

encouraged to invite personnel (cross-professional) to a wardbased education on the issue. We have no detailed information about whether and how the ward-based education was performed, but HCWs attendance is indicated by the HCWs' self-reports.

\section{Hand hygiene audits}

The intention of the audits was to promote hand hygiene and draw the HCWs' attention towards the topic by (1) performing audits and (2) presenting ward-based results. The ICCs were trained to observe events requiring hand hygiene during their colleagues' duties. The decision of when and how hand hygiene should be performed was based on national guidelines, and the audit gave a percentage of compliance. The quality of data is not suitable for evaluating the programme. Hand hygiene audits were performed twice a year following a standardised observation protocol. The infection control team analysed and presented the overall results in ICNews and provided each ICC with wardspecific results.

\section{Questionnaire}

A structured questionnaire was developed in cooperation with the Norwegian Knowledge Centre for the Health Services. The target population was HCWs with direct contact with patients in a medical or surgical ward and in at least a $75 \%$ position. The population consisted of 693 persons, including 159 physicians (159), 386 nurses and 148 nurses' assistants. Minimum sample size was estimated to 100 , and the questionnaire was sent to a randomised selection of $150 \mathrm{HCWs}$ and distributed proportionally among each profession: 33 physicians, 85 nurses and 32 nurses' assistants. The questionnaire was sent by the internal mail system and answers were anonymous to the researchers. A system to follow non-respondents was established.

\section{Data analysis}

SPSS V.15.0 was used to describe and analyse the data. To investigate the association between the interventional strategy and the HCWs' reports on knowledge and behaviour, we measured OR and corresponding 95\% CI using Fisher's exact test. $\mathrm{p}$ Values $<0.05$ were defined as statistically significant.

\section{RESULTS}

The questionnaire was returned by 111 of the $150 \mathrm{HCWs}$ (74\%). The response rate among physicians, nurses and nurse assistants was 59.4 (19 of 32), 83.5 (71 of 85) and 63.6 (21 of 33), respectively. $86.5 \%$ of the HCWs were aware of ICNews and $86.5 \%$ were aware of the ICCs. In table 2, the results from the questionnaire are summarised.

For each issue the mean number of HCWs who read ICNews was 43.1 (variation 21 to 71). The readers of ICNews reported hand hygiene and infection surveillance as the most relevant issues (table 3).
Those who did not read ICNews reported reasons as lack of time $(16.2 \%)$ and poor availability of ICNews (18\%) most often. Only two persons answered that the ICNews was not interesting, whereas four persons reported that it was not relevant for his or her work.

There was no significant difference between the professions in self-reported effect on refreshed knowledge after reading ICNews (table 4), but in reports on behavioural change, the odds ratio for being a nurse/nurse assistant was 4.30 (CI 1.37 to 13.47, p 0.017) compared to that for being a physician.

The HCWs reported that hand hygiene audits had an impact on compliance, but there were no significant differences between professions (table 5).

\section{DISCUSSION}

ICNews was an effective way to reach $>80 \%$ of the HCWs. This is an important aspect in hospital settings as the target group is large and resources limited. Among those who actually read ICNews, $92.9 \%$ reported that their knowledge was refreshed and $60.6 \%$ reported behavioural change. Taking into account that ICNews was not read by all the respondents, an overall impact of $74.8 \%$ on knowledge and $49.5 \%$ on behaviour made this longterm intervention a well-targeted initiative.

This study has a descriptive study design. We were not able to limit the distribution of ICNews to certain areas of the hospital to provide a control group. However, the questionnaire was distributed to a random sample of HCWs in medical and surgical wards.

The design did not include data before and after the intervention, and the results are based on data from HCWs' selfreports. In a systematic review by Davis et al, the authors conclude that physicians rarely self-assess accurately and that the physicians with a low clinical performance had an impaired ability to self-assess accurately. ${ }^{8}$ The self-reported data in this study can be affected by HCWs' overstatement in change of behaviour and knowledge. The possible inaccuracy of the data due to this bias makes it difficult to draw ultimate conclusions on objective performance outcomes. However, we cannot ignore the fact that the infection control programme reached out to $>80 \%$ of the respondents and influenced HCWs' intentions to change behaviour in infection control.

Intentions are not sufficient to actually perform behavioural changes. However, results from studies of theory of planned

Table 2 The figures summarises the HCWs' report from the questionnaire

\begin{tabular}{|c|c|c|}
\hline HCWs' self-report through questionnaire & Yes, n (\%) & $\begin{array}{l}\text { Not answ } \\
\text { n }(\%)\end{array}$ \\
\hline Do you know what ICNews is? & $96(86.5)$ & $4(3.6)$ \\
\hline Have you read one or more issues of ICNews? & $84(75.7)$ & $7(6.3)$ \\
\hline $\begin{array}{l}\text { Did reading of ICNews refresh your knowledge in } \\
\text { infection control? }\end{array}$ & $83(74.8)$ & $22(19.8)$ \\
\hline $\begin{array}{l}\text { Did reading ICNews make you change behaviour } \\
\text { related to infection control? }\end{array}$ & $55(49.6)$ & $26(23.4)$ \\
\hline Do you know that there is an ICC in your ward? & $96(86.5)$ & $2(1.8)$ \\
\hline Have you attended the ICCs ward education? & $70(63.1)$ & 0 \\
\hline $\begin{array}{l}\text { Have your knowledge in infection control been } \\
\text { refreshed through attending the ICC ward education? }\end{array}$ & $64(57.7)$ & $42(37.8)$ \\
\hline $\begin{array}{l}\text { Have you changed behaviour related to infection } \\
\text { control through attending the ICC ward education? }\end{array}$ & $58(52.3)$ & $42(37.8)$ \\
\hline Are you aware of the ICCs' hand hygiene audits? & $89(80.2)$ & $7(6.3)$ \\
\hline $\begin{array}{l}\text { Did hand hygiene audits improve your hand hygiene } \\
\text { compliance? }\end{array}$ & $73(65.8)$ & $17(15.3)$ \\
\hline
\end{tabular}

HCWs, healthcare workers; ICC, infection control link contacts; ICNews, Infection Control Newsletter. 
Table 3 The percentage of readers of ICNews who reported the issue in question as relevant and/or interesting

\begin{tabular}{lll}
\hline Issues of ICNews & $\begin{array}{l}\text { Percentage of HCWs } \\
\text { who found the issue } \\
\text { relevant }\end{array}$ & $\begin{array}{l}\text { Percentage of HCWs } \\
\text { who found the issue } \\
\text { interesting }\end{array}$ \\
\hline Hand hygiene & 90.1 & 67.6 \\
Infection surveillance & 90.0 & 90.0 \\
Isolation precautions & 88.1 & 69.0 \\
The model of ICCs & 87.5 & 62.5 \\
MRSA & 86.4 & 81.4 \\
Blood stream infections & 81.0 & 90.4 \\
Blood injuries & 80.9 & 68.1 \\
EpiGen and Department & 62.5 & 66.7 \\
of Microbiology & & 61.5 \\
Vaccination & 61.5 & \\
\hline
\end{tabular}

HCWs, healthcare workers; ICC, infection control link contacts; ICNews, Infection Control Newsletter.

behaviour suggest that intention is the cause of a planned behaviour. $^{9-11}$ In a study about attitudes and perceptions towards hand hygiene, Pessoa-Silva et al ${ }^{12}$ show that $75 \%$ of HCWs believed that they could improve hand hygiene compliance. We look at behavioural change as a stepwise process where acknowledgement of a need to change behaviour and intentions to do it is one important step. To implement intention into action is a further step and beyond the scope of this study.

Intentions to improve hand hygiene are associated with expectations from colleagues and superiors, capacity to perform the procedure and perception of campaigns. ${ }^{13}$ We believe that the success of our intervention could be explained by comparable factors. The monthly reminder function of our programme make us believe that the normative aspect of behaviour will follow and gradually form a constructive culture for infection control in the hospital. Lack of knowledge about infection control guidelines and their scientific background is reported by HCWs as a barrier for performance of hand hygiene. ${ }^{2}{ }^{4-6}$ Therefore, each issue of ICNews was introduced by an article that summarised scientific references and guidelines. The authors aimed to present the guidelines in a way that made it easy to comply. ${ }^{15} 16$

A recent Cochrane review concludes that audit and feedback to improve professional practice have small to moderate effects. ${ }^{14-16}$ However, studies have shown that using repeated feedback on hand hygiene and surveillance results improve compliance and reduce the infection rates. ${ }^{14}{ }^{17-19}$ In our study, the HCWs reported infection surveillance as the most interesting and relevant issue. This could be an important a motivational factor, and we believe that performance of audits related to hand hygiene or other procedures could be of great value as interventional means and measures of interventional effects.

The only significant difference between the professions was the influence on self-reported behavioural change after reading ICNews. Although the physicians reported that reading ICNews refreshed their knowledge, few reported that the intervention resulted in behavioural changes. We have no proper data to explain this phenomenon, but one reason might be the low attendance to ward-based education by physicians. ICNews

Table 4 HCWs who reported refreshed knowledge and/or behavioural change after reading ICNews

\begin{tabular}{llr}
\hline & Knowledge & \multicolumn{1}{c}{ Behaviour } \\
\hline Nurses/nurse assistants & $65 / 70(92.9 \%)$ & $49 / 68(72.1 \%)$ \\
Physicians & $17 / 17(100 \%)$ & $6 / 16(37.5 \%)$ \\
Total & $82 / 87(94.3 \%)$ & $55 / 84(65.5 \%)$ \\
\hline
\end{tabular}

HCWs, healthcare workers; ICNews, Infection Control Newsletter.
Table 5 Table 5The number of HCWs who reported improvement in hand hygiene compliance as a result of hand hygiene audits

\begin{tabular}{lc}
\hline & Improved compliance \\
\hline Nurses and nurse assistants & $62 / 77(80.5 \%)$ \\
Physicians & $9 / 15(60.0 \%)$ \\
Total & $71 / 92(77.2 \%)$ \\
\hline
\end{tabular}

HCWs, healthcare workers.

alone was possibly not sufficient to change behaviour. Single educational interventions to improve adherence to guidelines in infection control most often give short-term changes in HCWs' behaviour and only a few have proven sustained behavioural effects. ${ }^{3}{ }^{17-19}$ The impact of written information as a single intervention is uncertain, but a key factor of our intervention was the additional promotion of ICNews and ward-based education by the ICCs. ${ }^{20-22}$

As our intervention had an impact on nurses and nurse assistants' reports on infection control behaviour, this study supports the importance of a long-term and multimodal approach to improve quality performance. The time and resources spent to produce and distribute ICNews was an effective way to reach out to a large number of HCWs. In the future it is desirable to make a more substantial influence of the physicians, as several studies have concluded that physicians' compliance in hand hygiene is lower than among other HCWs. ${ }^{23}$ We believe that ICNews has a strong potential to improve infection control behaviour in our hospital, but the following improvements should be implemented:

- Adding more information on hospital infection rates in ICNews;

- Performing hand hygiene audits in a methodological reliable way;

- Make the infections control team responsible for educational sessions adjusted to the physicians' time schedule.

Acknowledgements The authors wish to thank the Infection Control Department for initiative and implementation of ICNews. In particular, we thank Silje S. Saetre for following up data collection.

Funding The study has not been sponsored by external sources.

\section{Competing interests None.}

Provenance and peer review Not commissioned; externally peer reviewed

\section{REFERENCES}

1. Pittet D, Harbarth S. The intensive care unit. In: Bennet JV V, Brachman PS,eds Hospital infections. Philadelphia: Lippincott-Raven Publishers, 1998:381-402.

2. Siegel JD, Rhinehart $\mathrm{E}$, Jackson $\mathrm{M}$, et al. Management of multidrug-resistant organisms in healthcare settings, 2006. Am J Infect Control 2007;35:165-93.

3. Pittet D, Hugonnet $S$, Harbarth $S$, et al. Effectiveness of a hospital-wide programme to improve compliance with hand hygiene. Infection Control Programme. Lancet 2000:356:1307-12

4. Pittet D. Improving compliance with hand hygiene in hospitals. Infect Control Hosp Epidemiol 2000;21:381-6

5. Pittet D, et al. WHO guidelines on hand hygiene in health care. 2005. Ref type: report

6. Boyce JM, Pittet D. Guideline for hand hygiene in health-care settings: recommendations of the Healthcare Infection Control Practices Advisory Committee and the HICPAC/SHEA/APIC/IDSA Hand Hygiene Task Force. Infect Control Hosp Epidemiol 2002;23:S3-40.

7. Quiros D, Lin S, Larson EL. Attitudes toward practice guidelines among intensive care unit personnel: a cross-sectional anonymous survey. Heart Lung 2007;36:287-97.

8. Davis DA, Mazmanian PE, Fordis M, et al. Accuracy of physician self-assessment compared with observed measures of competence. JAMA 2006:296:1092-102.

9. Jenner EA, Fletcher BC, Watson P, et al. Discrepancy between self-reported and observed hand hygiene behaviour in healthcare professionals. J Hosp Infect 2006;63:418-22.

10. O'Boyle CA, Henly SJ, Larson E. Understanding adherence to hand hygiene recommendations: the theory of planned behavior. Am J Infect Control 2001;29:352-60.

11. Moret L, Tequi B, Lombrail P. Should self-assessment methods be used to measure compliance with handwashing recommendations? A study carried out in a French university hospital. Am J Infect Control 2004;32:384-90. 
12. Pessoa-Silva CL, Posfay-Barbe K, Pfister R, et al. Attitudes and perceptions towards hand hygiene among healthcare workers caring for critically ill neonates. Infect Control Hosp Epidemiol 2005;26:305-13.

13. Sax H, Uçkay I, Richet $H$, et al. Determinants of good adherence to hand hygiene among health care workers who have extensive exposure to hand hygiene campaigns. Infect Control Hosp Epidemiol 2007;28:1267-74.

14. Delgado-Rodriguez M, Gomez-Ortega A, Sillero-Arenas M, et al. Efficacy of surveillance in nosocomial infection control in a surgical service. Am J Infect Control 2001:29:289-94.

15. Sykes PK, Brodribb RK, McLaws ML, et al. When continuous surgical site infection surveillance is interrupted: the Royal Hobart Hospital experience. Am J Infect Control 2005;33:422-7.

16. Jamtvedt G, Young JM, Kristoffersen DT, et al. Audit and feedback: effects on professional practice and health care outcomes. Cochrane Database Syst Rev 2006: CD000259. Issue 2. doi:10.1002/14651858.CD000259.pub2.
17. Naikoba S, Hayward A. The effectiveness of interventions aimed at increasing handwashing in healthcare workers - a systematic review. J Hosp Infect 2001;47:173-80.

18. Larson EL, Early E, Cloonan P, et al. An organizational climate intervention associated with increased handwashing and decreased nosocomial infections. Behav Med 2000:26:14-22.

19. Pittet D. Improving adherence to hand hygiene practice: a multidisciplinary approach Emerg Infect Dis 2001:7:234-40.

20. Rea L, Cronk S, Conly J. An infection control bulletin as an educational tool: is it useful? Can J Infect Control 1992; 7:45-7.

21. Robert J, Renard L, Grenet K, et al. Implementation of isolation precautions: role of a targeted information flyer. J Hosp Infect 2006;62:163-5.

22. O'Brien MA, Rogers S, Jamtvedt G, et al. Educational outreach visits: effects on professional practice and health care outcomes. Cochrane Database Syst Rev 2007; CD000409. Issue 4. doi: 10.1002/14651858.CD000409.pub2

23. Pittet D. Compliance with handwashing in a teaching hospital. Infect Control Hosp Epidemiol 1999:126:126-30. 